\title{
THE EFFICIENCY OF SYRINGE STOMACH FLUSHING IN DIET SAMPLING OF SALMONIDS
}

\author{
Jelena ČANAK ATLAGIĆ ${ }^{*}$, Ana MARIĆ ${ }^{2}$, Jelena ĐUKNIĆ ${ }^{1}$, Stefan ANDJUS ${ }^{1}$, Nikola \\ MARINKOVIĆ ${ }^{1}$, Momir PAUNOVIĆ ${ }^{1}$, and Predrag SIMONOVIĆ ${ }^{1,2}$ \\ ${ }^{1}$ Institute for Biological Research "Siniša Stanković”, National Institute of Republic of Serbia, \\ University of Belgrade, Belgrade, Serbia \\ ${ }^{2}$ Faculty of Biology, University of Belgrade, Belgrade, Serbia
}

Čanak Atlagić J., Marić A., Đuknić J., Andjus S., Marinković N., Paunović M., Simonović P. 2019. The efficiency of syringe stomach flushing in diet sampling of salmonids. Acta Ichthyol. Piscat. 49 (4):319-327.

Background. A sampling of stomach and intestine content is usually performed by dissection of the gastrointestinal tract of fish. To avoid fish sacrificing, various non-lethal techniques have been developed and tested. Such sampling methods are very useful, especially for small populations and protected species. In this study, a modified syringe stomach flushing was applied on Oncorhynchus mykiss (Walbaum, 1792), and Salmo trutta Linnaeus, 1758, to test its efficiency in retrieving stomach content.

Materials and methods. Water was injected repeatedly by a syringe through a silicone tube directly into the stomach of live fish to flush the content out. Afterwards, fish were dissected to collect residual stomach content. The efficiency of the method was assessed as the percentage of flushed content by weight and as the percentage of the number of flushed prey items, both in respect to the whole stomach content (100\%). The relation between the fish body size (length and weight) and efficiency of flushing (expressed as the weight and number of flushed prey) was tested by linear regression. The sensitivity of the method was tested with respect to 25 designated prey types. The share of each prey type was compared in the pooled sample of flushed and residual content.

Results. Collected stomach content was well preserved for identification of ingested organisms. From 25 designated prey types, 17 were $100 \%$ flushed, 4 over $90 \%$, one over $80 \%$, 2 were $44 \%$ effectively flushed (gastropods and caddisflies in stone cases), and 1 prey type was present only in the residual sample (Gordius sp.). The efficiency of the method assessed as the mean percentage of flushed content by weight was found to be $78.78 \%$, while $91.99 \%$ of prey items were effectively flushed.

Conclusion. The applied modification of syringe stomach flushing was found to be effective for investigation of stomach content of salmonid fish since (1) collected prey items were well preserved and easily identified; (2) the percentage of flushed prey items was high (91.99\%); and (3) the method is easily applicable and inexpensive.

Keywords: fish diet sampling, stomach content, syringe flushing, non-lethal method, salmonids

\section{INTRODUCTION}

Analysis of fish diet is of interest in fisheries biology and ecological studies of salmonids (Johnson 1976, Merrick et al. 1992, Wipfli 1997, Fochetti et al. 2003), as well as of other fish species (Politou et al. 1993, Piria et al. 2005). Fish sacrificing is not favoured by the scientific community for ethical and conservational reasons. Some species are rare, valuable, or have low population numbers, so eliminating specimens of such species can have serious consequences on population structure and its genetic diversity (Reed and Frankham 2003). Nevertheless, complete removal of stomach and intestine content is usually performed by dissection of the gastrointestinal tract of fish. To avoid the sacrifice of the fish various techniques for obtaining diet samples from live fish have been developed, tested and discussed (Robertson 1945, Seaburg 1957, Foster 1977, Giles 1980, Hyslop 1980, Strange and Kennedy 1981, Light et al. 1983, Culp et al. 1988, Hartleb and Moring 1995, Shuman and Peters 2007, Sánchez-Hernández et al. 2010, Hafs et al. 2011, Braga et al. 2017). Use of rigid tubes, stomach suction, application of emetics, forceps insertion, gastroscopic viewing, syringe flushing and combinations of nonlethal methods for diet sampling, were compared and discussed by Kamler and Pope (2001).

Syringe flushing can be used in two ways, one is to inject water through the anal opening (Baker and Fraser 1976) and other is to inject water through the mouth to flush content from the stomach (Meehan and Miller 1978), 
in both cases, contents are flushed out through the mouth. In this study, flushing of the stomach content was chosen as a standardized method, which should always collect content from the same portion of the fish gastrointestinal tract, only from the stomach. Digested material is less expected in the stomach content in comparison to the intestine content, which helps in the analysis of the samples. According to previous research, the syringe stomach flushing is considered as an effective method for extracting the stomach content (Foster 1977, Meehan and Miller 1978, Strange and Kennedy 1981, Light et al. 1983, Hafs et al. 2011, Braga et al. 2017). An advantage of this method is that the fish should stay fit and alive after the procedure. Meehan and Miller (1978) tested the method on coho salmon, Oncorhynchus kisutch (Walbaum, 1792), cutthroat trout, Oncorhynchus clarki (Richardson, 1836), and rainbow trout, Oncorhynchus mykiss (Walbaum, 1792). According to their study, stomach flushing of rainbow trout had an efficiency of $90 \%$ based on flushed prey items, and $77 \%$ efficiency based on the weight of the flushed content. Meehan and Miller (1978) used a syringe and a hollow needle. Giles (1980) used two connected syringes with tubes; one syringe was used for injecting of water and other for making suction. In the presently reported study, a modification of the flushing method was applied, gastric lavage was performed using a single syringe (like in Meehan and Miller 1978) with a longer silicon tube attached to its tip (similar as in Giles 1980), without suction. Two sizes of syringes $(20 \mathrm{~mL}$ and 50 $\mathrm{ml}$ ) and size matching tubes ( $3 \mathrm{~mm}$ and $5 \mathrm{~mm}$ diameter) were used for smaller and bigger fish respectively. The same approach was used in the study of age-0 brook trout Salvelinus fontinalis (Mitchill, 1814), where stomach flushing was done with a $5 \mathrm{~mL}$ syringe and a catheter tube (Hafs et al. 2011), which corresponds to flushing of smaller fish in the presently reported study. Braga et al. (2017) also used a syringe $\left(60 \mathrm{~cm}^{3}\right)$ and a silicon tube (1 $\mathrm{mm}$ diameter) and tested it on small Neotropical catfish.

In the presently reported study, rainbow trout, Oncorhynchus mykiss was chosen as a first-choice model organism. Highland streams in the Republic of Serbia (where the study was conducted) are typically inhabited by native brown trout Salmo trutta Linnaeus, 1758 (see Simonović 2001), yet these populations are of great conservational interest as valuable genetic stocks (Laikre 1999). The sacrifice of individuals from such populations should be avoided or reduced to a minimum, even for scientific research purposes. On the other hand, feral rainbow trout, an allochthonous species escaping from aquaculture facilities (Simonović 2001) is also present in salmonid streams, why using them in this type of research is more justifiable. Similar general ecological characteristics (primarily feeding behaviour), stomach anatomy, close taxonomical relations of two species, as well as the fact that they can live in the same water body in sympatry, meet the criteria for both species to be used as a valid model system for our study.

Aims of this study were: (1) to test the modified method efficiency for investigation of salmonid fish taxa; (2) to test whether the method efficiency depends of fish weight and length; (3) to test if the method causes injuries of the stomach; (4) to test if the sampled stomach content was preserved enough to allow identification of prey items; and (5) to test sensitivity of the method for different prey types.

\section{MATERIAL AND METHODS}

Sampling offish and body measuring. Allfishwere sampled using electrofishing gear AquaTech device IG200ce (input $12 \mathrm{~V}$ per maximum $15 \mathrm{~A} \mathrm{DC}$, output $500 \mathrm{~V}$ and frequency $65 \mathrm{~Hz}$ ). Rainbow trout individuals were sampled from two rivers in the Republic of Serbia, 4 individuals from the Rasina River $\left(43^{\circ} 30^{\prime} 20.4^{\prime \prime} \mathrm{N}, 020^{\circ} 51^{\prime} 24.6^{\prime \prime} \mathrm{E}\right)$ and 12 individuals from the Mlava River $\left(44^{\circ} 12^{\prime} 03.0^{\prime \prime} \mathrm{N}, 021^{\circ} 44^{\prime} 57.4^{\prime \prime} \mathrm{E}\right)$. Also, 4 individuals of brown trout from the Mlava River were included in the study. It was decided to include these brown trout in the study since they suffered great stress form electrical shock and it was evident that they would not recover. It was not intended to sacrifice more individuals from this species. Before stomach flushing, all fish were weighed $(W)$ to the nearest $g$, and the standard body length (SL) and total body length (TL) were measured to the nearest $\mathrm{mm}$.

Syringe stomach flushing, description of the applied method. The method used in this study was a modification of the method used in Giles (1980) and Meehan and Miller (1978). In the presently reported study, two sizes of syringes (of $20 \mathrm{~mL}$ and $50 \mathrm{~mL}$ ) and silicon tubes $(3 \mathrm{~mm}$ and $5 \mathrm{~mm}$ in diameter) were used for stomach flushing of different sizes of fish (total lengths $8-10 \mathrm{~cm}$ and over 10 $\mathrm{cm}$; Fig. 1 and 2, respectively). Syringe and tube sizes were impromptu matched with the mouth gape size. When the 5 $\mathrm{mm}$ tube was too big to go through the mouth opening or it were going through but not leaving any space for water and flushed organisms to come out, the smaller tube and syringe was used. It required two people to perform the flushing: one held the fish (caudal fin up, head down) at an angle of approx. $30^{\circ}$ to the collecting sieve (mesh size $0.5 \mathrm{~mm}$ ); the other inserted the tube through the oesophagus into the stomach and injected water repeatedly until there was no more content to wash out (Fig. 2). The emptiness of the stomach was palpable, i.e., could be felt when fingers were placed over the fish stomach. Massaging the abdomen while flushing was performed to help loosen the contents and to facilitate the procedure. When larger prey was an obstacle to the water flow, the tube was moved back and forth while injecting water to ease washing out of the stomach content. Recovery, residual stomach content, and potential stomach injuries. After the flushing procedure, rainbow trout were left for half an hour in aerated containers with fresh cold water to test recovery and survival after the procedure. The brown trout were not tested for survival since they were heavily stressed by electric shock before conducting the syringe flushing, so the survival and recovery would be strongly influenced by their initial state. In this study, no anaesthetic was used before performing of measuring and flushing since fish were handled right after being caught and still relatively calm as a result of electrofishing effect. After measuring, flushing, and testing the survival, fish were dissected. Before dissection, the 


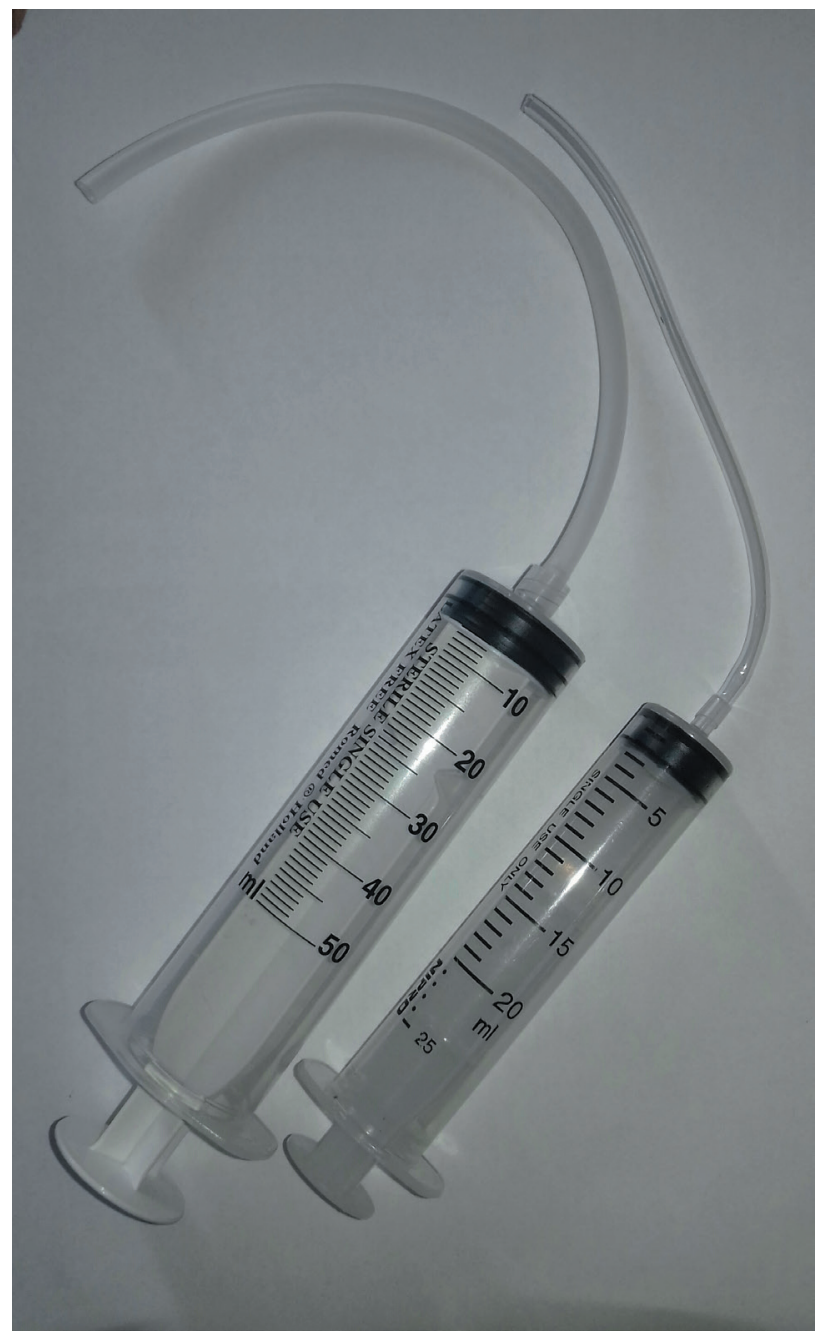

Fig. 1. Two syringes $(50 \mathrm{~mL}$ and $20 \mathrm{~mL})$ with attached silicon tubes, diameter $3 \mathrm{~mm}$ and $5 \mathrm{~mm}$, used for stomach flushing

fish were placed in a plastic container with a lethal dose of anaesthetic MS-222 (250 $\left.\mathrm{mg} \cdot \mathrm{L}^{-1}\right)$. The stomach was opened to its pyloric constriction to search for residual content, as well as for possibly visible injuries caused by the procedure. The flushed and residual diet samples were separately stored and fixed using 96\% ethanol.

Effectiveness of syringe stomach flushing. Numeric and gravimetric methods for evaluating the efficiency were used and the efficiency was shown as the mean percentage with standard deviation (SD) of flushed prey items and weight of the flushed content. For each individual fish extracted and the residual diet material were separately dried on a paper towel to collect excess ethanol and weighed on an analytical balance with a sensitivity of $10^{-4} \mathrm{~g}$. After determining the weight, the preys were counted and identified under the stereomicroscope at $50 \times$ magnification. Flushed and residual content together were considered $100 \%$ of the stomach content, same for weight and the number of prey items. Both flushed and residual prey organisms were counted and identified to the ecological group level (aquatic insects to the order or family level, other invertebrates to the class level).

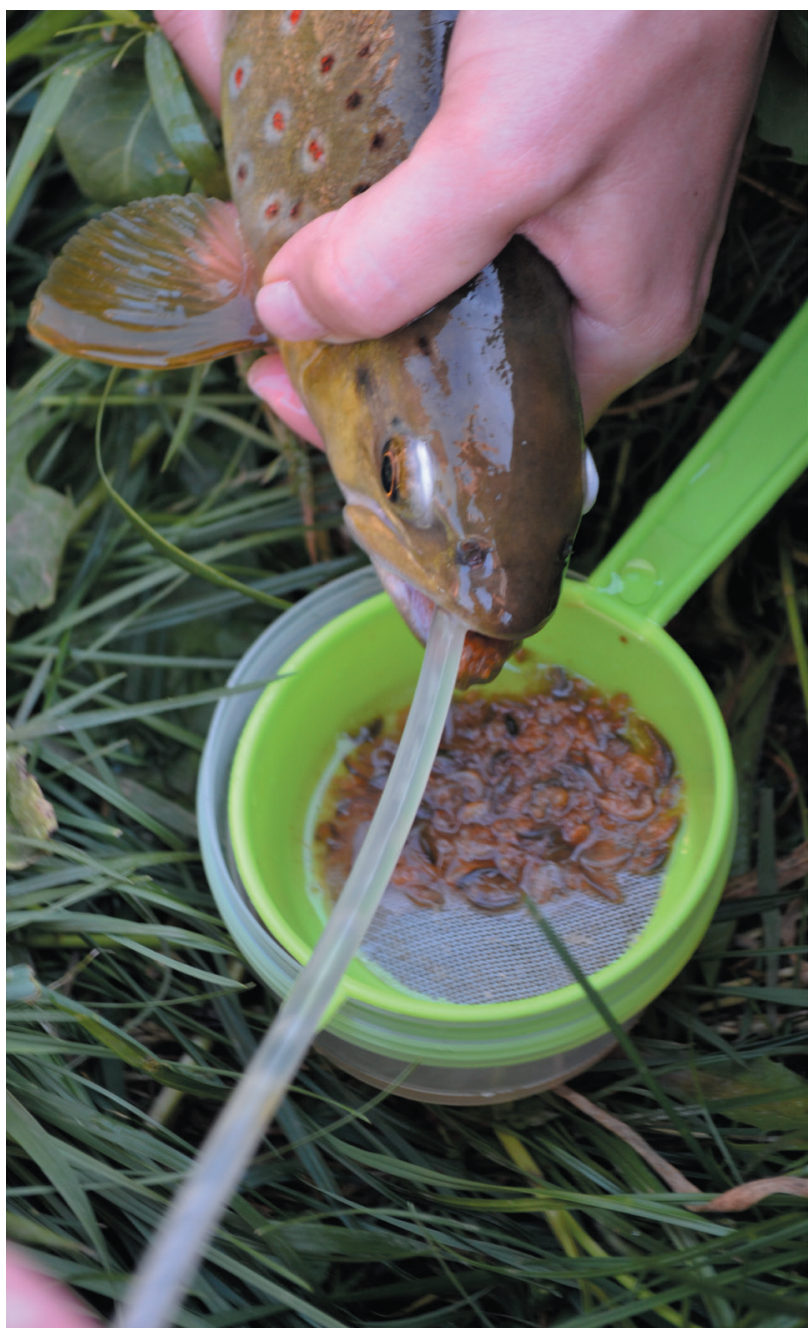

Fig. 2. Syringe stomach flushing and collection of the fish diet sample

Indigestible parts of the prey were not removed when weighing, e.g., caddisfly (Trichoptera) cases, shells of clams (Bivalvia), and freshwater snails (Gastropoda).

Linear regression was done to test whether the method efficiency is influenced by fish size. Two brown and three rainbow trout had empty stomachs, therefore data for 13 rainbow and 2 brown trout were included in the regression analysis. Standard length (SL) was taken as an explanatory variable, while the efficiency of flushing was a dependent variable, based on the weight of the flushed content $\left(E_{w}\right)$ and the number of flushed organisms $\left(E_{n}\right)$. The regression was also run for the weight $(W)$ as another body size measure. The body weight $(W)$ was taken as an explanatory variable, while the efficiency of flushing was a dependent variable, based on the weight of the flushed content $\left(E_{w}\right)$ and the number of flushed organisms $\left(E_{n}\right)$.

Method sensitivity for different prey types. The extracted stomach content of all fish was identified to the nearest taxon and sorted in 25 types of pray which belong to certain taxonomic groups and share common characteristics. Terrestrial insects were represented by several different genera but with similar size and characteristics so were 
considered as one prey type. Formicidae were separated from other terrestrial insects because they were smaller in size and very numerous in the samples.

To test whether different kinds of prey were unequally gathered by the flushing method, the presence and numbers of 25 designated types of prey in flushed and residual diet samples were compared. All flushed samples were pooled together, and the same was performed with residual samples. The significance of differential presence was tested with the nonparametric Wilcoxon test. Another approach for assessing sensitivity was to calculate the mean $( \pm \mathrm{SD})$ flushing efficiency for each prey type: a sum of flushing efficiencies for each fish that had a certain prey type in the content of their stomachs was divided by number of these individuals; this was done for each prey type respectively.

\section{RESULTS}

All rainbow trout survived the procedure of electrofishing, measuring, and subsequent stomach flushing, and showed complete recovery after a $10-15$ min rest in an aerated container. In all 20 fish, the procedure did not cause any visible physical damage to the stomach wall.

The body measurements of 20 analysed fish are given in Table 1. The mean body size for brown trout was 12.05 $\pm 5.32 \mathrm{~cm}$ (TL), $10.25 \pm 4.53 \mathrm{~cm}(\mathrm{SL}), 29.5 \pm 37.88 \mathrm{~g}(W)$, and for rainbow trout $19.06 \pm 6.58 \mathrm{~cm}$ (TL), $16.46 \pm 5.75$ $\mathrm{cm}(\mathrm{SL})$, and $97.12 \pm 104.19 \mathrm{~g}(W)$.

Three of the 16 sampled rainbow trout had empty stomachs, ascertained both by flushing and dissection. The stomachs of seven fish were $100 \%$ effectively flushed, with no residual content in the dissected stomach. Residual content was found in the stomachs of six dissected fish (Table 1). Two of four brown trout had empty stomachs, the third one was $100 \%$ effectively flushed, and in the fourth residual content was found (Table 1).

The total weight of the consumed prey in the total sample of both rainbow and brown trout obtained by flushing was $9.597 \mathrm{~g}(68.93 \%)$, and the weight of the residual content was $4.268 \mathrm{~g}(31.06 \%)$ (Table 1, Fig. 3). The total number of consumed prey items in the whole sample obtained by flushing was 1579 (95.92\%), and the number of residual prey items was 67 (4.07\%) (Table 1, Fig. 4).

The efficiency ascertained as a mean $( \pm \mathrm{SD})$ showed $78.78 \%( \pm 30.46 \%)$ efficiency for the weight of flushed content and $91.99 \%( \pm 21.715 \%)$ efficiency for the number of flushed organisms (prey items). Efficiency by weight ranged from $9.09 \%$ to $100 \%$, while efficiency for flushed organisms ranged from $16.67 \%$ to $100 \%$ (Table 1 ).

Linear regression showed no dependence between fish length (SL) and efficiency ( $E$ in \%), expressed either as the weight of the flushed content $\left(E_{w}=87.302-0.5033 \times\right.$ SL, $\left.R^{2}=0.0104, P=0.700\right)$, or expressed as the number of flushed prey $\left(E_{n}=0.904 \times \mathrm{SL}+76.662, R^{2}=0.0659, P\right.$ $=0.356)$. There was no dependence between fish weight $(W)$ and both efficiency parameters $\left(E_{w}=87.75-0.0859\right.$ $\times W, R^{2}=0.095, P=0.265$, and $E_{n}=0.0248 \times W+89.38$, $\left.R^{2}=0.0155, P=0.658\right)$.

Organisms collected from the stomachs by flushing were, in general, well preserved (Fig. 5), although some

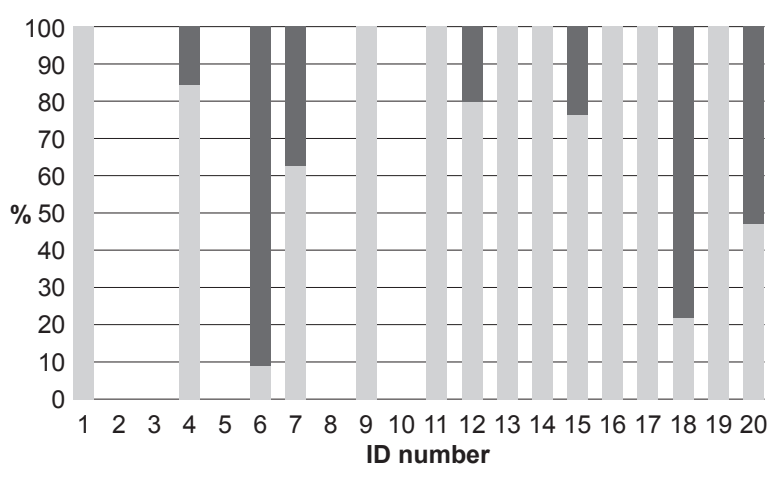

weight of flushed content (\%) weight of residual content (\%)

Fig. 3. Efficiency of the method, presented as the percentage of weight for flushed and residual contents for each fish, Salmo trutta (ID 1 to 4) and Oncorhynchus mykiss (ID 5 to 20)

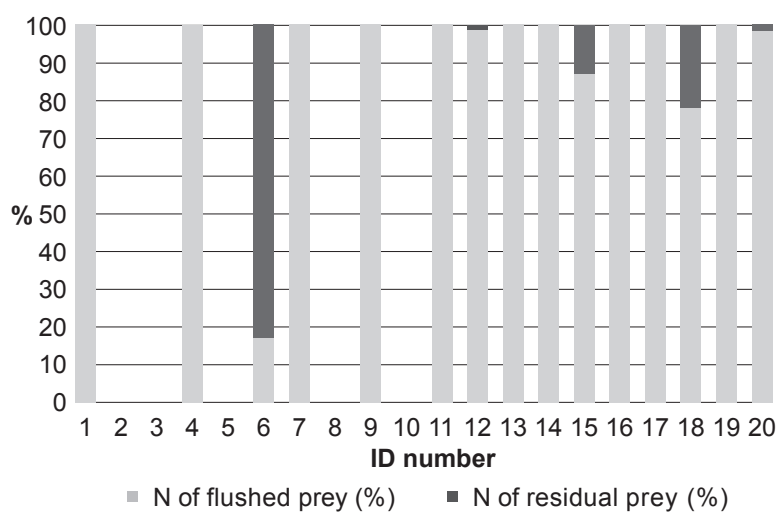

Fig. 4. Efficiency of the method presented as the percentage of the number of flushed and residual prey items for each fish, Salmo trutta (ID 1 to 4) and Oncorhynchus mykiss (ID 5 to 20)

digested material (DM) that could not be clearly identified was present in some of the samples (Table 2).

Diet samples are presented as the number of each identified prey type in Table 2, for both flushed and residual samples. Non-biting midge pupae (Diptera: Chironomidae), Gammarus sp. (Crustacea: Gammaridae), and ants (Insecta: Formicidae) were the most numerous preys. The presence and numbers of 25 designated prey types in flushed and residual diet samples are presented in Fig. 6A and 6B. A significant difference in sensitivity of the method towards prey types was confirmed by the Wilcoxon test $(N=25, T=16.5, Z=3.928, P<0.0001)$.

When flushed samples were pooled together and compared with pooled residual samples to assess sensitivity for 25 designated prey types, the following results were obtained: 17 prey types were $100 \%$ flushed, 4 over 90\% (Chironomidae pupae (99.43\%), Gammarus sp. $(99.05 \%)$, Formicidae (95\%), and Coleoptera adults $(90.91 \%)$ ), one $83 \%$ (terrestrial Insecta), 2 were $44.44 \%$ effectively flushed (Ancylus sp. and Trichoptera in cases), and 1 prey type i.e., Gordius sp. was present only in the residual sample. Only caddisflies with stone cases, Gastropoda (Ancylus sp.) and Gordioidea worms were 
Table 1

Fish sampled characteristics and gravimetric and numerical data of stomach contents obtained by flushing for two trout species Salmo trutta and Oncorhynchus mykiss

\begin{tabular}{|c|c|c|c|c|c|c|c|c|c|c|c|c|}
\hline \multirow{3}{*}{ ID } & \multirow{3}{*}{ Species } & \multirow{3}{*}{$\begin{array}{c}\mathrm{TL} \\
{[\mathrm{cm}]}\end{array}$} & \multirow{3}{*}{$\begin{array}{c}\mathrm{SL} \\
{[\mathrm{cm}]}\end{array}$} & \multirow{3}{*}{$\begin{array}{c}W \\
{[\mathrm{~g}]}\end{array}$} & \multicolumn{4}{|c|}{ Content weight } & \multicolumn{4}{|c|}{ Number of organisms } \\
\hline & & & & & Flushed & Residual & Flushed & Residual & Flushed & Residual & Flushed & Residual \\
\hline & & & & & {$[\mathrm{g}]$} & {$[\mathrm{g}]$} & {$[\%]$} & {$[\%]$} & & & [\%] & [\%] \\
\hline 1 & S. trutta & 8.3 & 7.0 & 7 & 0.038 & 0.000 & 100.00 & 0.00 & 15 & 0 & 100.00 & 0.00 \\
\hline 2 & & 8.7 & 7.2 & 5 & 0.000 & 0.000 & 0.00 & 0.00 & 0 & 0 & 0.00 & 0.00 \\
\hline 3 & & 10.0 & 8.8 & 11 & 0.000 & 0.000 & 0.00 & 0.00 & 0 & 0 & 0.00 & 0.00 \\
\hline 4 & & 21.2 & 18.0 & 95 & 0.310 & 0.057 & 84.47 & 15.53 & 35 & $\mathrm{DM}$ & 100.00 & 0.00 \\
\hline 5 & O. mykiss & 10.8 & 9.0 & 13 & 0.000 & 0.000 & 0.00 & 0.00 & 0 & 0 & 0.00 & 0.00 \\
\hline 6 & & 10.8 & 9.0 & 13 & 0.004 & 0.040 & 9.09 & 90.91 & 1 & 5 & 16.67 & 83.33 \\
\hline 7 & & 12.3 & 10.8 & 19 & 0.184 & 0.109 & 62.80 & 37.20 & 76 & DM & 100.00 & 0.00 \\
\hline 8 & & 13.4 & 11.8 & 30 & 0.000 & 0.000 & 0.00 & 0.00 & 0 & 0 & 0.00 & 0.00 \\
\hline 9 & & 16.4 & 13.0 & 37 & 0.257 & 0.000 & 100.00 & 0.00 & 17 & 0 & 100.00 & 0.00 \\
\hline 10 & & 15.9 & 13.7 & 48 & 0.000 & 0.000 & 0.00 & 0.00 & 0 & 0 & 0.00 & 0.00 \\
\hline 11 & & 17.0 & 14.2 & 57 & 0.530 & 0.000 & 100.00 & 0.00 & 136 & 0 & 100.00 & 0.00 \\
\hline 12 & & 17.2 & 15.4 & 52 & 0.243 & 0.061 & 79.93 & 20.07 & 80 & 1 & 98.77 & 1.23 \\
\hline 13 & & 18.6 & 15.5 & 59 & 0.569 & 0.000 & 100.00 & 0.00 & 78 & 0 & 100.00 & 0.00 \\
\hline 14 & & 17.0 & 15.8 & 50 & 0.563 & 0.000 & 100.00 & 0.00 & 26 & 0 & 100.00 & 0.00 \\
\hline 15 & & 19.0 & 16.0 & 87 & 1.310 & 0.405 & 76.38 & 23.62 & 321 & 46 & 87.47 & 12.89 \\
\hline 16 & & 22.0 & 19.5 & 113 & 2.286 & 0.000 & 100.00 & 0.00 & 37 & 0 & 100.00 & 0.00 \\
\hline 17 & & 21.5 & 19.9 & 86 & 0.369 & 0.000 & 100.00 & 0.00 & 30 & 0 & 100.00 & 0.00 \\
\hline 18 & & 29.6 & 25.0 & 257 & 0.414 & 1.477 & 21.89 & 78.11 & 33 & 9 & 78.57 & 21.43 \\
\hline 19 & & 30.2 & 26.1 & 235 & 0.577 & 0.000 & 100.00 & 0.00 & 47 & 0 & 100.00 & 0.00 \\
\hline 20 & & 33.2 & 28.7 & 398 & 1.943 & 2.176 & 47.17 & 52.83 & 647 & 11 & 98.33 & 1.68 \\
\hline
\end{tabular}

$\mathrm{TL}=$ total length, $\mathrm{SL}=$ standard length, $W=$ body weight, $\mathrm{DM}=$ indistinguishable digested material.

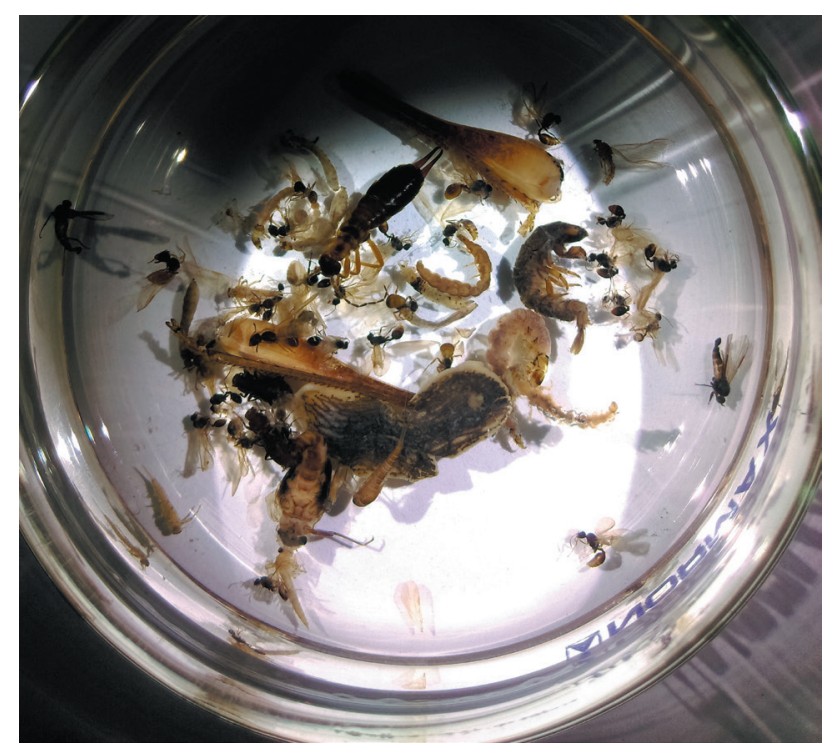

Fig. 5. Stomach content of one Oncorhynchus mykiss specimen obtained by the syringe flushing method more present in residual samples than in flushed samples, while other prey types were very effectively flushed.

Similar results were obtained when sensitivity was assessed as the mean flushing efficiency for each prey type: 17 prey types were $100 \%$ flushed, Chironomidae pupae were $99.82 \%( \pm 0.51 \%)$ effectively flushed, Formicidae $97.18 \%( \pm 6.31 \%)$, Gammarus sp. 93.33\% ( $\pm 22.22 \%)$, terrestrial Insecta $76.89 \%( \pm 43.67 \%)$, Trichoptera in cases $72.22 \%$ ( $\pm 48.11 \%)$, Ancylus sp. $33.33 \%( \pm 57.73 \%)$, and Gordius sp. was present only in the residual sample.

\section{DISCUSSION}

According to Hyslop (1980) and Kamler and Pope (2001), stomach flushing or gastric lavage is the most effective nonlethal method used for diet sampling. Variations of the method have been applied for diet analyses of different fish species since the late 1940s. Robertson (1945) used a glass tube and a suction bulb; Seaburg (1957) used two tube apparatus, with inlet tube connected with a suction bulb, and a bigger outlet tube which was connected to a collecting jar; Foster (1977) used an electric pump for pulsed gastric lavage, Meehan and Miller (1978) used syringe with a hollow needle; 
Table 2

Counted and identified prey items found in flushed and residual samples for all specimens of Salmo trutta (ID 1 and 4) and Oncorhynchus mykiss (ID 6 to 20) included in the study that had any content in the stomach

\begin{tabular}{|c|c|c|c|c|c|c|c|c|c|c|c|c|c|c|c|c|c|c|c|c|c|c|}
\hline \multirow{2}{*}{ ID number } & \multirow{2}{*}{$\begin{array}{l}1 \\
\mathrm{~A}\end{array}$} & \multicolumn{2}{|c|}{4} & \multicolumn{2}{|c|}{6} & \multicolumn{2}{|c|}{7} & \multirow{2}{*}{$\begin{array}{l}9 \\
\mathrm{~A}\end{array}$} & \multirow{2}{*}{$\frac{11}{\mathrm{~A}}$} & \multicolumn{2}{|c|}{12} & \multirow{2}{*}{$\begin{array}{c}13 \\
\mathrm{~A}\end{array}$} & \multirow{2}{*}{$\begin{array}{c}14 \\
\mathrm{~A}\end{array}$} & \multicolumn{2}{|c|}{15} & \multirow{2}{*}{$\begin{array}{c}16 \\
\mathrm{~A}\end{array}$} & \multirow{2}{*}{$\frac{17}{\mathrm{~A}}$} & \multicolumn{2}{|c|}{18} & \multirow{2}{*}{$\begin{array}{l}19 \\
\mathrm{~A}\end{array}$} & \multicolumn{2}{|c|}{20} \\
\hline & & $\mathrm{F}$ & $\mathrm{R}$ & $\mathrm{F}$ & $\mathrm{R}$ & $\mathrm{F}$ & $\mathrm{R}$ & & & $\mathrm{F}$ & $\mathrm{R}$ & & & $\mathrm{F}$ & $\mathrm{R}$ & & & $\mathrm{F}$ & $\mathrm{R}$ & & $\mathrm{F}$ & $\mathrm{R}$ \\
\hline Oligochaeta & & & & & & & & & 1 & & & & & & & & & & & & & \\
\hline Nematoda & & & & & & & & & & & & & & & & & & & & & 1 & 0 \\
\hline Gordius sp. & & & & & & & & & & & & & & & & & & & & & 0 & 2 \\
\hline Turbellaria & & & & & & & & & & & & & & & & & & & & & 1 & 0 \\
\hline Ancylus sp. & & & & 0 & 2 & & & & 4 & & & & & & & & & 0 & 3 & & & \\
\hline Bivalvia & & & & & & & & 1 & & & & & & & & & & & & & & \\
\hline Gammarus sp. & 8 & & & 1 & 2 & & & 1 & & & & 74 & 26 & 2 & 0 & 3 & 23 & 28 & 0 & 43 & & \\
\hline Simuliidae & & & & & & & & & 8 & & & 1 & & 2 & 0 & & & 1 & 0 & & 10 & ( \\
\hline Chironomidae larvae & 1 & & & & & & & & 1 & & & & & & & 3 & & 1 & 0 & & 5 & 0 \\
\hline Chironomidae pupae & 6 & 1 & 0 & & & 75 & 0 & 9 & & 79 & 1 & & & & & & 1 & & & 3 & & \\
\hline Chironomidae adults & & & & & & & & 1 & 1 & & & 1 & & & & & & & & & & \\
\hline Other Diptera & & & & & & & & 1 & 4 & & & & & & & 4 & & & & & 2 & c \\
\hline Plecoptera & & & & & & & & & & & & & & & & 3 & & & & & & \\
\hline Ephemeroptera larvae & & & & & & & & & 78 & & & & & 9 & 0 & 9 & & 1 & 0 & & 29 & 0 \\
\hline Ephemeroptera adults & & 2 & 0 & & & & & & & & & & & 13 & 0 & & 1 & & & & 9 & 0 \\
\hline Trichoptera in cases & & 2 & 0 & & & & & & & & & & & & & 1 & & 1 & 5 & & & \\
\hline Trichoptera & & 1 & 0 & & & & & 1 & 2 & & & & & 2 & 0 & 1 & & & & 1 & 7 & 0 \\
\hline Coleoptera larvae & & & & & & & & & 5 & & & & & 1 & 0 & 5 & & & & & 1 & 0 \\
\hline Coleoptera adults & & 3 & 0 & & & & & & 2 & & & & & & & 3 & & & & & 2 & 1 \\
\hline Heteroptera adults & & 9 & 0 & & & & & & & & & & & & & & & & & & & \\
\hline Terrestrial Insecta & & 1 & 0 & 0 & 1 & & & 3 & 4 & & & 2 & & 23 & 2 & 3 & 4 & 0 & 1 & & 10 & 6 \\
\hline Formicidae & & 11 & 0 & & & & & & 25 & & & & & 268 & 44 & & 1 & & & & 570 & 2 \\
\hline Aranea & & 5 & 0 & & & 1 & 0 & & 1 & 1 & 0 & & & 1 & 0 & & & & & & & \\
\hline $\begin{array}{l}\text { Terrestrial } \\
\text { Gastropoda }\end{array}$ & & & & & & & & & & & & & & & & 2 & & & & & & \\
\hline Fish & & & & & & & & & & & & & & & & & & 1 & 0 & & & \\
\hline TOTAL & 15 & 35 & $\mathrm{dm}$ & 1 & 5 & 76 & $\mathrm{dm}$ & 17 & 136 & 80 & 1 & 78 & 26 & 321 & 46 & 37 & 30 & 33 & 9 & 47 & 647 & 11 \\
\hline
\end{tabular}

$\mathrm{F}=$ flushed, $\mathrm{R}=$ residual, $\mathrm{A}=$ all content flushed $(100 \%), \mathrm{dm}=$ digested material.

Giles (1980) used two connected syringes for flushing and suction; Light et al. (1983) used apparatus similar with one used in Foster (1977) but with a help of compression sprayer tank; Culp et al. (1988) constructed more complicated apparatus with two syringes that can be used both for gut and anal flushing; Shuman and Peters (2007) tested a pulsed gastric lavage designed by Foster (1977) on a shovelnose sturgeon Scaphirhynchus platorynchus (Rafinesque, 1820); Sánchez-Hernández et al. (2010) tested the Seaburg's (1957) apparatus on Salmo trutta; Hafs et al. (2011) used a syringe and a catheter tube on age-0 brook trout Salvelinus fontinalis; Braga et al. (2017) also used a syringe with a tube for small catfish. The syringe stomach flushing is suitable for salmonids that are predatory species with a well-defined stomach, as was shown in Meehan and Miller (1978) for three salmonid species (Oncorhynchus mykiss, O. kisutch, and O. clarki), and in Hafs et al. (2011) for brook trout.

The method used in the presently reported study was modified from Meehan and Miller (1978), Culp et al. (1988), and Giles (1980). Giles (1980) used two syringes connected by a rubber band, one was used to inject water in $(20 \mathrm{~mL})$ and the other $(50 \mathrm{~mL})$ was used to make suction and to collect the prey items. We assumed that only small prey would be collected by suction since the tube diameter and syringe opening would restrict the collection of larger prey. Thus, it was decided not to use suction but to flush the content out only with the force of injected water, as in Meehan and Miller (1978) and Culp et al. (1988), with a note that Culp used Ringer's solution, not water. Meehan and Miller (1978) also used a syringe, but with a hollow needle on its tip. Instead, in this study, it was chosen to use silicone tubes that are flexible, longer, and could be inserted deeper in the stomach, yet they are soft and did not cause injury, as reported in Giles (1980) and Culp et al. (1988). Hafs et al. (2011) also used a syringe and a silicon tube, but it was tested only on small fish, age- 0 brook trout, and flushing was done with only three repetitions. Furthermore, it was conducted in the laboratory environment where fish were fed with only one type of prey (Ephemeroptera, Plecoptera, and caseless Trichoptera, respectively), and flushed soon after feeding (after $30 \mathrm{~min}$ ). In our study fish were caught in the field where they were feeding naturally with available aquatic macroinvertebrates and terrestrial organisms that get caught in the drift. Another study that used a syringe and 

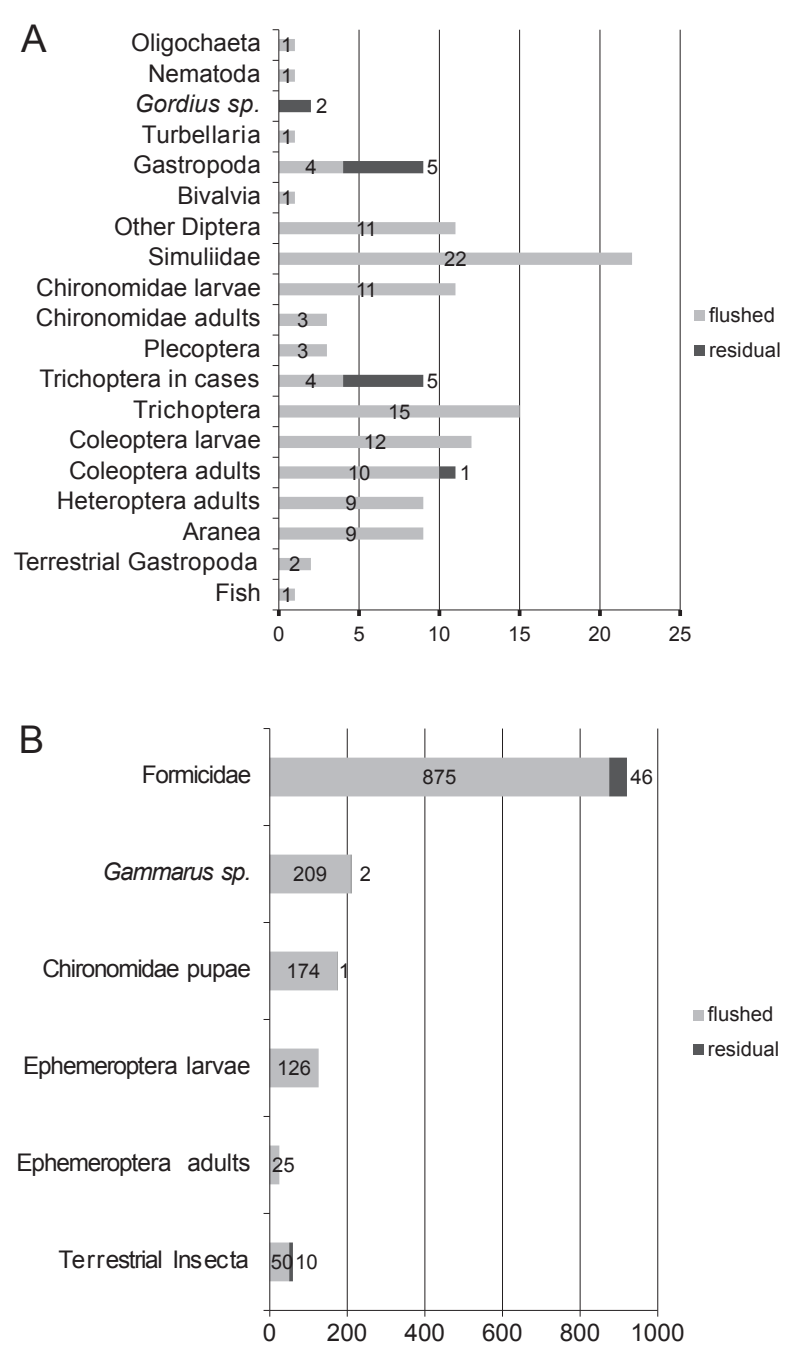

Fig. 6. Differential presence and number of prey items (x axis) in flushed vs. residual samples; (A) Prey types present with fewer than 25 items in flushed samples, (B) Prey types present with more than 25 items in flushed samples

a tube for flushing was done on small species of catfish (Braga et al. 2017).

There were no false empty stomach results. All five empty stomachs were confirmed to be empty by dissection. Visible injuries and death caused by the method were not recorded. In this study fish were not anaesthetized prior measuring and stomach flushing, yet if larger number of fish is caught and kept longer in the container so it has more time to recover from the first shock caused by electrofishing, some anaesthetic in low dosage could be used to calm it down before flushing if needed (100 mg . $\mathrm{L}^{-1}$ dosage of MS-222 is adequate and does not affect the survival according to Hafs et al. (2011); another option is clove oil solution ( $10 \%$ of clove oil, $40 \%$ of $70 \%$-alcohol, and $50 \%$ of water) as recommended in Braga et al. (2017)).

The total weight of the flushed diet in the total sample of both rainbow and brown trout was $9.597 \mathrm{~g}$ (68.93\%) with $78.78 \%$ mean efficiency of flushing, which corresponds to $77 \%$ efficiency that Meehan and Miller (1978) reported. The total number of flushed prey items in the total sample was 1579 (95.92\%) with $91.99 \%$ mean efficiency of flushing, which is a slightly better result than $90 \%$ obtained in the study of Meehan and Miller (1978). In the study of Hafs et al. (2011), in which similar modification of the method was used, very high efficiency was reported (98\% by the number of flushed prey). However, the study was conducted on brook trout that were fed with only one prey type in an experimental environment and only on age- 0 (about $5 \mathrm{~cm}$ long) fish. Neither growth nor survival of this small fish was negatively influenced by stomach flushing.

Hyslop (1980) claimed that gravimetric measurements of stomach contents usually over-emphasize the contribution of single heavy items to the diet. In Meehan and Miller (1978), hard non-digestible material was removed before weighing (caddisfly cases, wood debris, etc.). If shells and cases are discarded, other indigestible materials should also be discarded, such as the exoskeleton of most insects. However, all those items were both ingested and flushed, i.e., were in the stomach content. For this reason, in this study, all of the material was weighed and nothing was discarded. Nevertheless, choosing not to eliminate indigestible material can affect the results of efficiency estimated by weight. Thus, sample 12 would be close to $100 \%$ efficiency by weight and number of organisms, since the residual material consisted of only one non-biting midge pupa and a piece of wood that contributed to almost all of the weight. The same applied to sample 18 where 5 caddisfly larvae with stone cases were in the residual sample. Hence, efficiency in this study would show to be even greater if indigestible material had been discarded.

This method displayed a bias towards some types of prey. Large, heavy, or items covered with spikes and hooks were more prone to become lodged and unreachable by the applied method (Meehan and Miller 1978, Strange and Kennedy 1981), which was confirmed by the presence of residual caddisflies in stone cases and grasshopper legs in samples 15 and 20. Also, gastropods were one group that was more present in residual than in flushed samples, presumably because of the shape of their shell (Ancylus sp.). Another group that was present exclusively in the residual sample of one fish was Gordioidea worms (two specimens), with very long, slender bodies. Only caddisflies with stone cases, gastropods, and Gordioidea worms were more present in residual samples than in flushed samples, while other prey types were very effectively flushed. Prey types that were less effectively flushed were not that abundant in the total sample, and other that were present in greater number were all very effectively flushed (Fig. 6A, 6B). Similar results were obtained when sensitivity was assessed as the percentage of pooled flushed prey items and as the mean flushing efficiency for each prey type. Only one significant difference in assessed sensitivity was for Trichoptera in cases ( $44 \%$ vs. $72.22 \% \pm 48.11 \%$ ).

The flushing of Trichoptera in cases ranged from $16.67 \%$ to $100 \%$, which resulted in higher mean efficiency, yet also high standard deviation.

Additionally, in all fish, the residual content (except Gordius sp.) was located at the most distal part of the 
stomach. It was compactly pressed between the stomach walls and ready to pass to the intestine. Similar results were presented in Meehan and Miller (1978). It is obvious that results differ when the efficiency is assessed according to the weight of the sampled diet and according to the number of prey items. If the species and number of prey items are of interest the method can be considered very efficient and easily applicable. Hafs et al. (2011), reported that certain family of Ephemeroptera was less effectively flushed than others (Heptagenidae), in this study, all Ephemeroptera were 100\% effectively flushed (Baetidae and Heptagenidae were present).

No significant dependence between fish body size (length or weight) and efficiency of flushing (expressed as the weight and number of flushed prey) was observed, yet this result is based on a small data set and should be tested further, with more samples and on bigger fish (in this study only three were over $25 \mathrm{~cm}$, the largest was $28.7 \mathrm{~cm}$ SL). Same dependence was tested in Meehan and Miller (1978) on three trout species with more samples (155 fish samples). In their study, bigger fish tended to have more residual contents after flushing, regardless of the species. This was explained by stronger pyloric constriction that decreased water flow. Strange and Kennedy (1981) rather explain this as a fact that bigger fish consumes bigger prey, which tends to be lodged. Sánchez-Hernández et al. (2010), who tested the Seaburg's pump on brown trout, concluded that the flushing efficiency depends more on the prey's morphological characteristics, stomach fullness and extent of food digestion than on the fish size. In the study of Hafs et al. (2011) morphology of prey was believed to be more influential on efficiency than stomach fullness.

According to this study, if stomach flushing is performed with many repeated injections of water and plenty of content is collected, it could be wrongly assumed that all of the content was washed out and stop the procedure too soon. Therefore, it is advisable to continue flushing until clear water with no organisms appears, no matter how many repetitions were performed before (however, this prolongs the time out of the water and exposes the fish to greater stress, which might influence its survival). Also, if some or no content comes out while performing the flushing and a full abdomen is still palpable, large prey (small fish, grasshopper, caddisfly with a heavy stone case, etc.) may be lodged, interfering with the flushing. If this is the case, the fish can be treated with another nonlethal method or even sacrificed and dissected to extract the entire diet sample if it is required. Using blunt tip forceps to remove the obstacle could help (if it is in the visible reach), but this can potentially injure the fish. In future studies, the situations when stomach content is present but cannot be gathered by flushing should be investigated further to propose an adequate solution, perhaps a combination of methods. Even though our results do not show that flushing of larger fish was less successful, it might be advisable to use mechanized water pressure for bigger fish to achieve greater efficiency.

\section{CONCLUSION}

Several methods based on injection of water showed efficiency over 90\%: study of Strange and Kennedy (1981) $99.3 \%$ for brown trout and juvenile salmon, Meehan and Miller (1978) 90\% for rainbow trout, 92\% for cutthroat trout and $99 \%$ for coho salmon, Hafs et al. (2011) reported $98 \%$ efficiency by number of flushed prey, Light et al. (1983) reported 98\% efficiency by weight of flushed content for brook trout and Foster (1977) nearly 100\% for grass pickerel and largemouth bass. According to these studies, flushing with different application and tools is an overall efficient approach for salmonids and some other predatory species.

According to the analysed data, the syringe stomach flushing method applied in the presently reported study can be considered reliable in terms of extracting most of the stomach content $(91.99 \%$ of prey items; $78.78 \%$ of weight). Additionally, methods efficiency does not depend on fish length or weight; however, this conclusion should be tested with a larger data set. Also, extracted items are well preserved and easily identified. However, it should be taken into consideration that few prey types could be biased in the diet sample, e.g., caddisflies in stone cases; same was reported for other similar methods (Meehan and Miller 1978, Strange and Kennedy 1981). Flushing with a syringe and a silicon tube proved to be very easy, inexpensive, and reliable in terms of efficiency, similar as methods used in previous studies (Meehan and Miller 1978, Strange and Kennedy 1981, Light et al. 1983, Hafs et al. 2011), especially when count and identification of prey was the main concern.

\section{ACKNOWLEDGEMENTS}

This study was supported by the Ministry of Education, Science and Technological Development of the Republic of Serbia; projects OI 173025 and TR 37009.

\section{REFERENCES}

Baker A.M., Fraser D.F. 1976. A method for securing the gut contents of small, live fish. Transactions of the American Fisheries Society 105 (4): 520-522. DOI: 10.1577/1548-8659(1976)105<520:AMFSTG>2.0.CO;2

Braga R.R., Ribeiro V.M., Bornatowski H., Abilhoa V., Vitule J.R.S. 2017. Gastric lavage for dietary studies of small fishes: Efficiency, survival and applicability. Acta Ichthyologica et Piscatoria 47 (1): 97-100. DOI: 10.3750/AIEP/02079

Culp J.M., Boyd I., Glozier N.E. 1988. An improved method for obtaining gut contents from small, live fishes by anal and stomach flushing. Copeia 1988 (4): 1079-1082. DOI: $10.2307 / 1445740$

Fochetti R., Amici I., Argano R. 2003. Seasonal changes and selectivity in the diet of brown trout in the River Nera (central Italy). Journal of Freshwater Ecology 18 (3): 437-444. DOI: 10.1080/02705060.2003.9663979

Foster J.R. 1977. Pulsed gastric lavage: An efficient method of removing the stomach contents of live fish. The Progressive Fish-Culturist 39 (4): 166-169. DOI: 10.1577/1548-8659(1977)39[166:PGL]2.0.CO;2 
Giles N. 1980. A stomach sampler for use on live fish. Journal of Fish Biology 16 (4): 441-444. DOI: 10.1111/j.1095-8649.1980.tb03722.x

Hafs A.W., Niles J.M., Hartman K.J. 2011. Efficiency of gastric lavage on age- 0 brook trout and the influence on growth and survival. North American Journal of Fisheries Management 31 (3): 530-534. DOI: 10.1080/02755947.2011.593955

Hartleb C.F., Moring J.R. 1995. An improved gastric lavage device for removing stomach contents from live fish. Fisheries Research 24 (3): 261-265. DOI: 10.1016/0165-7836(95)00390-V

Hyslop E.J. 1980. Stomach contents analysis-A review of methods and their application. Journal of Fish Biology 17 (4): 411-429. DOI: 10.1111/j.10958649.1980.tb02775.x

Johnson L. 1976. Ecology of arctic populations of lake trout, Salvelinus namaycush, lake whitefish, Coregonus clupeaformis, arctic char, S. alpinus, and associated species in unexploited lakes of the Canadian Northwest Territories. Journal of the Fisheries Research Board of Canada 33 (11): 2459-2488. DOI: 10.1139/f76-293

Kamler J.F., Pope K.L. 2001. Nonlethal methods of examining fish stomach contents. Reviews in Fisheries Science 9 (1): 1-11. DOI: 10.1080/20016491101663

Laikre L. (ed.) 1999. Conservation genetic management of brown trout (Salmo trutta) in Europe. Report by the concerted action on identification, management and exploitation of genetic resources in the brown trout (Salmo trutta). "Troutconcert"; EU Fair CT97-3882.

Light R.W., Adler P.H., Arnold D.E. 1983. Evaluation of gastric lavage for stomach analyses. North AmericanJournalofFisheries Management3(1):81-85. DOI: 10.1577/1548-8659(1983)3<81:EOGLFS $>2$. 0 . $\mathrm{CO} ; 2$

Meehan W.R., Miller R.A. 1978. Stomach flushing: Effectiveness and influence on survival and condition of juvenile salmonids. Journal of the Fisheries Research Board of Canada 35 (10): 1359-1363. DOI: 10.1139/f78-212

Merrick G.W., Hershey A.E., McDonald M.E. 1992. Salmonid diet and the size, distribution, and density of benthic invertebrates in an arctic lake. Hydrobiologia 240 (1-3): 225-233. DOI: 10.1007/BF00013464

Piria M., Treer T., Aničić I., Safner R., Odak T. 2005. The natural diet of five cyprinid fish species. Agriculturae Conspectus Scientificus 70 (1): 21-28.

Politou C.-Y., Economidis P.S., Sinis A.I. 1993. Feeding biology of bleak, Alburnus alburnus, in Lake Koronia, northern Greece. Journal of Fish Biology 43 (1): 3343. DOI: 10.1111/j.1095-8649.1993.tb00408.x

Reed D.H., Frankham R. 2003. Correlation between fitness and genetic diversity. Conservation Biology 17 (1): 230-237.DOI: 10.1046/j.1523-1739.2003.01236.x

Robertson O.H. 1945. A method for securing stomach contents of live fish. Ecology 26 (1): 95-96. DOI: $10.2307 / 1931919$

Sánchez-Hernández J., Servia García M.J., VieiraLanero R., Cobo F. 2010. Evaluación del lavado gástrico como herramienta para el análisis de la dieta en trucha común. Limnetica 29 (2): 369-378. DOI: 10.23818/limn.29.30

Seaburg K.G. 1957. A stomach sampler for live fish. The Progressive Fish-Culturist 19 (3): 137-139. DOI: 10.1577/1548-8659(1957)19[137:ASSFLF]2.0. $\mathrm{CO} ; 2$

Shuman D.A., Peters E.J. 2007. Evaluation of pulsed gastric lavage on the survival of captive shovelnose sturgeon. Journal of Applied Ichthyology 23 (4): 521524. DOI: 10.1111/j.1439-0426.2007.00887.x

Simonović P. 2001. Ribe Srbije. [Fishes of Serbia.] NNK Internacional Izdavaštvo, Belgrade, Serbia. [In Serbian.]

Strange C.D., Kennedy G.J. 1981. Stomach flushing of salmonids: A simple and effective technique for the removal of the stomach contents. Fisheries Management 12 (1): 9-15. DOI: 10.1111/j.13652109.1981.tb00002.x

Wipfli M.S. 1997. Terrestrial invertebrates as salmonid prey and nitrogen sources in streams: Contrasting old-growth and young-growth riparian forests in southeastern Alaska, U.S.A. Canadian Journal of Fisheries and Aquatic Sciences 54 (6): 1259-1269. DOI: 10.1139/f97-034

Received: 1 November 2018 Accepted: 1 May 2019 Published electronically: 15 December 2019 